THURSDAY, SEPTEMBER 9, I909.

A MONOGRAPH ON THE TRANSIT CIRCLE.

Les Observations méridiennes: Théorie et Pratique.

By F. Boquet. Tome Premier, Instruments et Méthodes d'Observation. Pp. xi+3i4. Tome Second, Corrections instrumentales et Equations Personelles. Pp. iv $+342+$ xii. (Paris: Octave Doin et Fils, I909.) Price, 2 vols., Io francs.

THESE two volumes comprise one of two completed sections out of a total of twenty-nine devoted to astronomy and celestial physics in a new form of scientific encyclopædia in which astronomy is only one of forty divisions. The whole work, if and when completed, should run to at least a thousand handy little volumes at a uniform price of 5 francs per volume. An index to the complete series is also promised, but it is hardly contemplated that the demand for the whole set will be very great, the idea being that each subject is to be totally distinct, so that a minimum of irrelevant matter need be purchased by any interested specialist, and that such sections as are rapidly rendered out-of-date may be quickly replaced by revised editions without necessitating alteration of the whole work.

Our purpose now, however, is to deal only with the two volumes before us, premising that the "Bibliothèque d'Astronomie et de Physique céleste," to which they belong, is under the directorship of M. Jean Mascart. It may be fairly remarked, inasmuch as the titles of the other twenty-eight sections of this "Library" are given, that it is quite possible the number will have to be augmented, as there is at present no obvious place for more than one modern investigation without straining the meaning of some of the published titles. With some 6oo pages entirely devoted to meridian observations, we are at first inclined to wonder why so much space was thought necessary. But the wonder does not last long, for the pages are quite small, and the amount of detail is very great, as is only fitting in an encyclopædia. Moreover, we soon perceive that the transit-circle, though the two parts are inevitably studied separately, is the only instrument considered. This strikes us as an error of omission, for there is no other place for discussion of the zenith telescope in any form. There is no mention of the various forms suggested in substitution for the ordinary one, such as the fixed telescope with meridian mirror or the transit with axis view, simply rotating in bearings east and west. A very possible explanation is that these various forms are not of much account in France, but their omission seems to be a mistake.

There does not seem to be much, if anything, of consequence omitted in reference to the transit circle itself, all kinds of instrumental errors being fully and carefully dealt with, several methods of determination or correction being given in many cases. For instance, a very clear account is given of Cowell's refraction tables as used at Greenwich, while division error and eccentricity, screw value and error, pivot error, wire intervals and inclination, flexure, and so on, are treated with great fulness. The printing chronograph in various forms is naturally conspicuous, this subject being one on which M. Boquet has written more than once before. Another subject with which he has similarly shown familiarity is given an importance we do not remember to have seen before, and that is personal equation, the adequate treatment of which is especially welcome. The various physiological or psychophysiological causes of error are very carefully differentiated, and at the same time no space is wasted on the numerous devices for determining absolute personal equation in transit observations, though a long list of references is given for the use of those who care to pursue the subject.

Perhaps those whose "eye-and-ear" observations are consciously or unconsciously taken by what may be called the chronometer comparison method, as distinct from Bradley's (M. Boquet calls it " méthode de l'œil et de 1'oreille par estime du temps"), will question whether their observations are so inferior as M. Boquet assumes. The use of screens also for magnitude equation is liable to meet with similar objections to those urged against the pierced cube of the Greenwich transit-circle, but in this the author is only summarising what has been done and projected. There are, in fact, very few places where he has expressed a decided personal opinion, so that we are inclined to regret that the plan of the work allowed so little scope for personality. With the reservation as to omissions to which we have alluded, we can only hope that the rest of the thousand-odd volumes will maintain the high standard of thoroughness set by $M$. Boquet.

W. W. B.

\section{THE HISTORY OF MECHANICS.}

Lectures de Mécanique. By E. Jouguet. Première Partie: La Naissance de la Mécanique. Deuxième Partie: L'Organisation de la Mécanique. Pp. $\mathrm{x}+$ 210 and 284. (Paris: Gauthier-Villars, r908-9.) Price 7.50 and io francs.

SINCE the eventful appearance of Mach's works on mechanics and heat, much greater interest has been shown in the historical development of applied mathematics, both for its own sake and from a growing conviction that the teacher of a subject ought to know something of its actual growth and expansion, as well as the current methods of expounding it. Recent works by M. Duhem show that even in France, the birthplace and home of clear-cut analytical systems, there is an appreciation of the value of historical research and of tracing the slow formation of the leading ideas and principles of mechanics.

For several reasons M. Jouguet's book will be found a useful supplement to its predecessors. In the first place he is an engineer, so that he is in full sympathy with such men as Stevinus and Huygens and Galileo, and gives considerable attention to those who, like Reich and Andrade, propose to deduce the laws of mechanics from actual experiment. At the same time he is by no means the case-hardened empiric who ignores the claims of logic, and despises speculation. In fact, it is noteworthy, and gratifying, that he prac. 